\title{
Correction to: Functional Quantization-Based Data Compression in Seismic Acquisition
}

\author{
Hamood ur Rehman Khan ${ }^{1}$ (D) - Salam A. Zummo ${ }^{1}$
}

Published online: 29 June 2018

(c) King Fahd University of Petroleum \& Minerals 2018

\section{Correction to: Arabian Journal for Science and \\ Engineering}

https://doi.org/10.1007/s13369-018-3367-z

Unfortunately, the Acknowledgment section was missing in the original article. It is given below.

Acknowledgements This research was supported by KFUPM through the Deanship of Scientific Research under Grant Number GTEC1403.

The original article can be found online at https://doi.org/10.1007/ s13369-018-3367-z.

Hamood ur Rehman Khan hamoodrak@kfupm.edu.sa

Salam A. Zummo

zummo@kfupm.edu.sa

1 Electrical Engineering Department, King Fahd University of Petroleum and Minerals, Dhahran 31261, Saudi Arabia 